Check for updates

Cite this: RSC Adv., 2017, 7, 28788

Received 13th April 2017 Accepted 18th May 2017

DOI: 10.1039/c7ra04196a

rsc.li/rsc-advances

\section{Facile synthesis of low band-gap DPP-EDOT containing small molecules for solar cell applications $\uparrow$}

\begin{abstract}
Venkatesan Govindan and Chun Guey Wu (iD *
Four donor-donor-acceptor-donor-donor (D1-D2-A-D2-D1) type small molecules (SM1, SM2, SM3 and SM4), in which diketopyrrolopyrrole (DPP) was used as an acceptor (DPP) core and 3,4ethylenedioxythiophene (EDOT), triphenylamine (TPA) or alkyl thiophene (AT) acted as a donor, were synthesized (by direct alkylation) for photovoltaic applications. The benzene flanked DPPs (SM1 and SM2) show more limited absorption and a lower-lying HOMO energy level compared to the thiophene flanked DPPS (SM3 and SM4, respectively), due to benzene being a poor donor compared to a thiophene moiety. SM3 and SM4 have absorptions extending to $750 \mathrm{~nm}$ (in $\mathrm{CH}_{2} \mathrm{Cl}_{2}$ ) and can be regarded as low band-gap small molecules. The inverted small molecule solar cell (using PCBM as an acceptor, and $\mathrm{ZnO}$ and $\mathrm{MoO}_{3}$ as the electron and hole transporters, respectively) based on SM2 has the highest value of $V_{\text {oc }}(0.82 \mathrm{~V})$ due to SM2 having the lowest HOMO level. An SM3 based device achieves the highest value of $J_{\text {sc }}(5.56$ $\mathrm{mA} \mathrm{cm}^{-2}$ ), due to the wide absorption profile and proper LUMO level. The poor photovoltaic performances of SM1 and SM4 (in which D1 is a triphenyl amine group) are due to the serious selfaggregation of the molecules in the SMx/PCBM active films. Two acceptor-donor-acceptor type (A-DA) molecules (SM5 and SM6) were also synthesized by Stille coupling, in which DPP and EDOT were used as the acceptor and donor, respectively, for the structure-photovoltaic performance study. The SM5 and SM6 films, having on-set absorption of up to $1000 \mathrm{~nm}$, can also be regarded as low band-gap small molecules. SM5 and SM6 are structural isomers, however the inverted cell based on SM6 has a much higher PCE than that based on SM5, due to SM6 having better solubility and a lower HOMO energy level. This study provides a guideline for the rational design and preparation of conjugated small molecules for organic solar cells.
\end{abstract}

\section{Introduction}

The solution processed organic solar cell is considered to be a viable route for realizing low-cost renewable energy. ${ }^{\mathbf{1 , 2}}$ Organic small molecules for solution processed bulk heterojunction (BHJ) solar cells (SMSCs) have attracted significant attention due to their well-defined molecular structures, easy purification, small batch to batch variations in their properties, and intrinsic monodispersity. ${ }^{3-5}$ A large number of papers have been published in the past several years regarding the synthesis, device engineering, and device physics of solution-processed SMSCs, and the devices based on small molecules have not achieved PCEs of higher than $10 \% .^{6}$ Further progress relies on molecular design and advanced device processing techniques. Diketopyrrolopyrrole (DPP), an industrial pigment with strong $\pi-\pi$ interaction, electron withdrawing characteristics and an

Department of Chemistry, National Central University, Jhong-Li, Taiwan, Republic of China.E-mail: t610002@cc.ncu.edu.tw

$\dagger$ Electronic supplementary information (ESI) available. See DOI: 10.1039/c7ra04196a efficient charge transport property, has emerged recently as one of the most widely used organic building blocks to construct molecules for organic field effect transistors (OFETs) ${ }^{7-10}$ and organic solar cells (OPVs). ${ }^{11-19}$ The relatively low lying HOMO levels make the DPP-containing molecules especially promising candidates for applications in organic solar cells to achieve high values of $V_{\mathrm{oc}}{ }^{20-23}$

Synthesizing new molecules with high yield and low waste for specific applications is a major challenge for the synthetic chemist. Recently, a new synthetic approach, namely the direct arylation (DCA) of $\mathrm{C}-\mathrm{H}$ bonds, was reported for preparing DPP derivatives. ${ }^{24-28}$ The direct $\mathrm{C}-\mathrm{H}$ arylation reaction has advantages over the traditional cross coupling reaction in terms of avoiding the use of organometallic precursor reagents, higher atom economy, fewer synthetic steps, higher yields and better compatibility with the functional groups. As a result, DCA has the advantages of a faster reaction rate, less expensive process and less waste production, hence making a substantial contribution to the development of sustainable chemistry. ${ }^{29-35}$ On the other hand, 3,4-ethylenedioxythiophene (EDOT) shows a strong electron donating ability. It can provide a noncovalent 

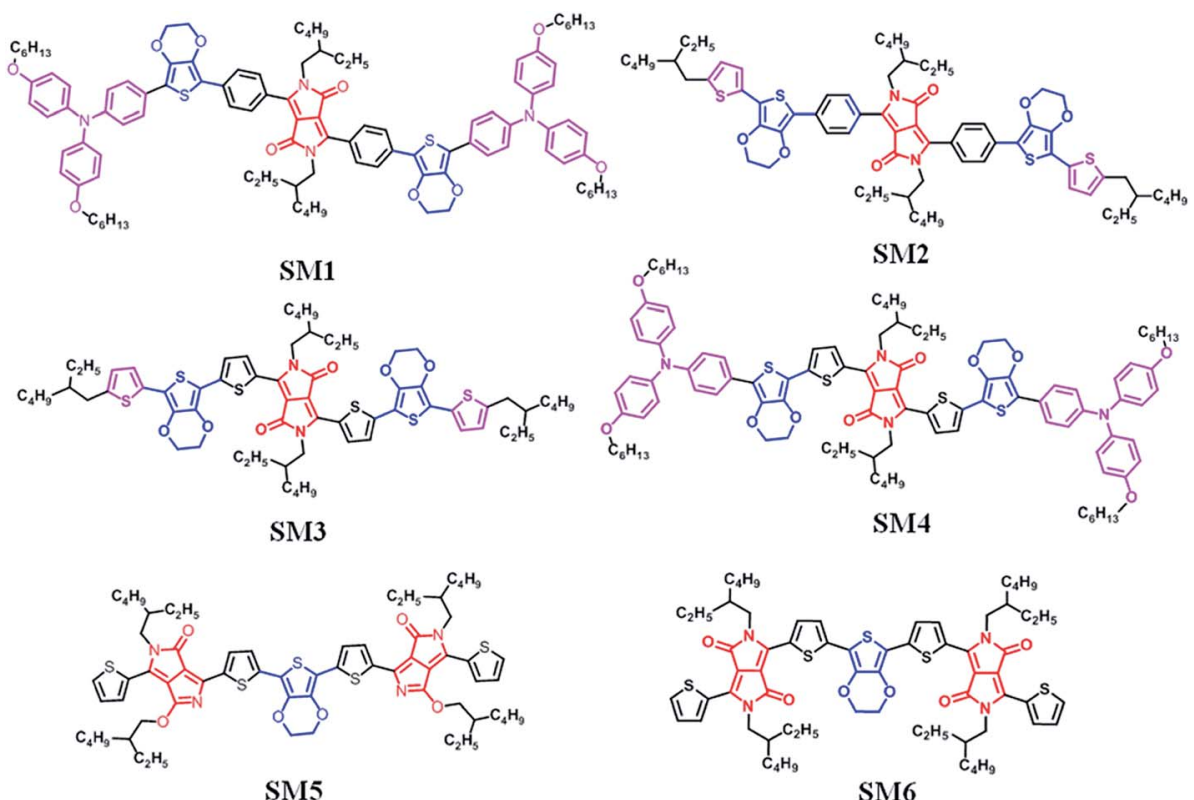

Fig. 1 Chemical structure of the DPP-based molecules SM1-6.

intermolecular interaction with the adjacent aryl units, thus inducing the self-rigidification of the conjugated system..$^{36-45}$ Therefore it was used widely as an electron donating moiety to combine with the DPP acceptor to construct push-pull or donor acceptor (D-A) p-type organic semiconductors. ${ }^{4-49}$

In the present work, we report the synthesis and physical properties of six new DPP containing small molecules, SM1-6, which were originally designed to be used in SMSCs. SM1-4, with D1-D2-A-D2-D1 molecular architectures, were synthesized by direct $\mathrm{C}-\mathrm{H}$ arylation, in which triphenylamine-EDOT or 2-ethylhexylthiophene-EDOT was used as a donating unit. Benzene flanked DPP (DPP $\left.[\mathrm{Ph}]_{2}\right)$ or thiophene flanked DPP $\left(\mathrm{DPP}[\mathrm{Th}]_{2}\right.$ ) was used as an acceptor. SM5 and SM6 (which are isomers) have an A-D-A type molecular architecture and were prepared by the Stille coupling reaction, in which EDOT was used as a donor and DPP was used as an acceptor. The chemical structures of the six molecules are shown in Fig. 1. The high photovoltaic small p-type molecule generally has a planarized molecular architecture, which was formed by large fused-ring moieties or intermolecular interactions. In this paper we used EDOT (a pseudo two dimension conjugated system ${ }^{50}$ ) as a donor unit to combine with the DDP acceptor and construct a planar small p-type molecule for SMSCs. The structure-physicochemical properties-photovoltaic performance relationship of these new compounds can provide valuable guidelines for designing new organic electronic materials. Moreover, we also demonstrated here that the green direct $\mathrm{C}-\mathrm{H}$ arylation reaction can be used to prepare organic compounds containing both EDOT and DPP units.

\section{Experimental section}

\subsection{Materials and physicochemical studies}

All chemicals, unless otherwise specified, were purchased from commercial resources and used as received. The ${ }^{1} \mathrm{H}$ NMR and
${ }^{13} \mathrm{C}$ NMR spectra were recorded with a Bruker $300 \mathrm{MHz}$ NMR spectrometer using $\mathrm{CDCl}_{3}$ as a solvent. The FAB-MS spectra were obtained using JMS-700 HR-MS. The UV/Vis absorption spectra were recorded using a Cary 300 Bio spectrometer. HPLC grade $\mathrm{CH}_{2} \mathrm{Cl}_{2}$ was purchased from ACROS Co. and distilled from $\mathrm{CaH}_{2}$ under an argon (Ar) atmosphere for electrochemical study. Tetra- $n$-butylammonium hexafluorophosphate $\left(\mathrm{TBAPF}_{6}\right)$ was recrystallized from ethanol twice and then stored in a desiccator before use. The glassy carbon electrode was polished with $0.05 \mathrm{~mm}$ alumina on Buehler felt pads and ultrasonicated for $2 \mathrm{~min}$ to remove the residue contamination. A platinum wire was used as the auxiliary electrode and the reference electrode was a home-made $\mathrm{Ag} / \mathrm{AgCl}$ (in $\mathrm{KCl}$ (sat'd)) electrode. The supporting electrolyte was $0.1 \mathrm{M}$ tetrabutylhexafluorophosphate $\left(\mathrm{TBAPF}_{6}\right) \mathrm{CH}_{2} \mathrm{Cl}_{2}$ solution. The square-wave voltammograms (frequency: $25 \mathrm{~Hz}$; step potential: $0.0051 \mathrm{~V}$; amplitude: $0.01995 \mathrm{~V}$ ) were recorded using a potentiostat/ galvanostat (PGSTAT 30, Autolab, Eco-Chemie, the Netherlands) and ferrocene was used as a calibration standard $(0.54 \mathrm{~V}$ versus $\mathrm{Ag} / \mathrm{AgCl}$ reference electrode).

\subsection{Synthesis of SM1-SM6}

SM1-4 were synthesized by the newly developed direct C-H arylation method. SM5 and SM6 were prepared with the wellknown Stille coupling reaction. The detailed synthetic procedures and structure analyses of the molecules are collected in the ESI. $\dagger$

\subsection{Device fabrication and photovoltaic properties characterization}

Inverted BHJ SMSCs with ITO/ZnO/SM $x: \mathrm{PCBM} / \mathrm{MoO}_{3} / \mathrm{Ag}$ architectures were fabricated in this study. The ITO-coated glass substrates were cleaned by ultrasonicating in deionized water, followed by acetone and isopropanol for $10 \mathrm{~min}$ each, and then 
dried under a stream of dry nitrogen. The cleaned ITO substrates were treated with UV-ozone for $10 \mathrm{~min}$. The ZnO film was prepared from its precursor solution of zinc acetate dihydrate $\left[\mathrm{Zn}\left(\mathrm{CH}_{3} \mathrm{COO}\right)_{2} \cdot 2 \mathrm{H}_{2} \mathrm{O}\right]$ in 2-ethoxyethanol and monoethanolamine (MEA) (1:1 in volume) using the spin-coating method in air. After spin-coating the SM $x$ :PCBM active layer in a glove box, a thin layer of molybdenum oxide was deposited on top of the active layer with a high vacuum thermal evaporator at an evaporation rate of $0.1 \AA \mathrm{s}^{-1}$. Ultimately, the $100 \mathrm{~nm}$ silver film was deposited on top of the molybdenum oxide layer as an electrode. The processes (composition and fabrication condition screening) for the device fabrication and photovoltaic property characterization are very similar to what we reported previously, unless specified. ${ }^{51}$

\section{Results and discussion}

\subsection{Synthesis}

The bromides of phenyl flanked DPP (DPP $\left.[\mathrm{Ph}]_{2} \mathrm{Br}_{2}\right)$, thienyl flanked DPP (DPP $\left[\mathrm{Th}_{2}\right]_{2} \mathrm{Br}_{2}$ ), and thienyl flanked DPPiso (DPPiso $[\mathrm{Th}]_{2} \mathrm{Br}$ ) were synthesized and purified following the reported procedures $^{52-55}$ with slight modifications. The procedures for preparing SM1-4 are outlined in Scheme 1. The direct $\mathrm{C}-\mathrm{H}$ arylation reaction was performed using $\mathrm{Pd}(\mathrm{OAc})_{2}$ as a catalyst and $\mathrm{K}_{2} \mathrm{CO}_{3}$ as a base at a temperature of $110{ }^{\circ} \mathrm{C}$. DPP $\left[\mathrm{Ph}_{2}\right]$ $\left[\mathrm{EDOT}_{2}\right]$ and $\mathrm{DPP}\left[\mathrm{Th}_{2}\right]\left[\mathrm{EDOT}_{2}\right]$ were synthesized by the $\mathrm{C}-\mathrm{H}$ arylation of $\mathrm{DPP}[\mathrm{Ph}]_{2} \mathrm{Br}_{2}$ and $\mathrm{DPP}[\mathrm{Th}]_{2} \mathrm{Br}_{2}$ in the presence of EDOT to get yields of $38 \%$ and $44 \%$, respectively. The molar ratio of $\mathrm{DPP}[\mathrm{Ph}]_{2} \mathrm{Br}_{2} / \mathrm{EDOT}$ was controlled to be $1: 2$ to avoid the formation of a polymer. A similar catalyst system, combining $\mathrm{Pd}(\mathrm{OAc})_{2}$ and $\mathrm{PCy}_{3} \cdot \mathrm{HBF}_{4}$, was used to proceed the reaction between $\mathrm{RO}-\mathrm{TPA}-\mathrm{Br}$ and the DPP derivatives to obtain SM1 and SM4 with yields of $46 \%$ and $41 \%$, respectively. The alkyl thiophene end capped SM2 and SM3 were prepared by brominating alkylthiophene with the corresponding DPP unit in dimethyl amine (DMA). The yields of SM2 and SM3 are 66\% and $62 \%$, respectively.

SM5 and SM6 were synthesized by Stille coupling using $\mathrm{Pd}\left(\mathrm{PPh}_{3}\right)_{4}$ as a catalyst and toluene as a solvent and using the processes displayed in Scheme 2. The Stille coupling between DPPiso[Th $]_{2} \mathrm{Br}$ and stannated EDOT afforded SM5 with a yield of $83 \%$. The same method was used for reacting $\mathrm{DPP}[\mathrm{Th}]_{2} \mathrm{Br}$ with stannated EDOT to obtain SM6 (yield: 78\%). The SM2, SM3 and SM6 molecules process good solubility in common organic
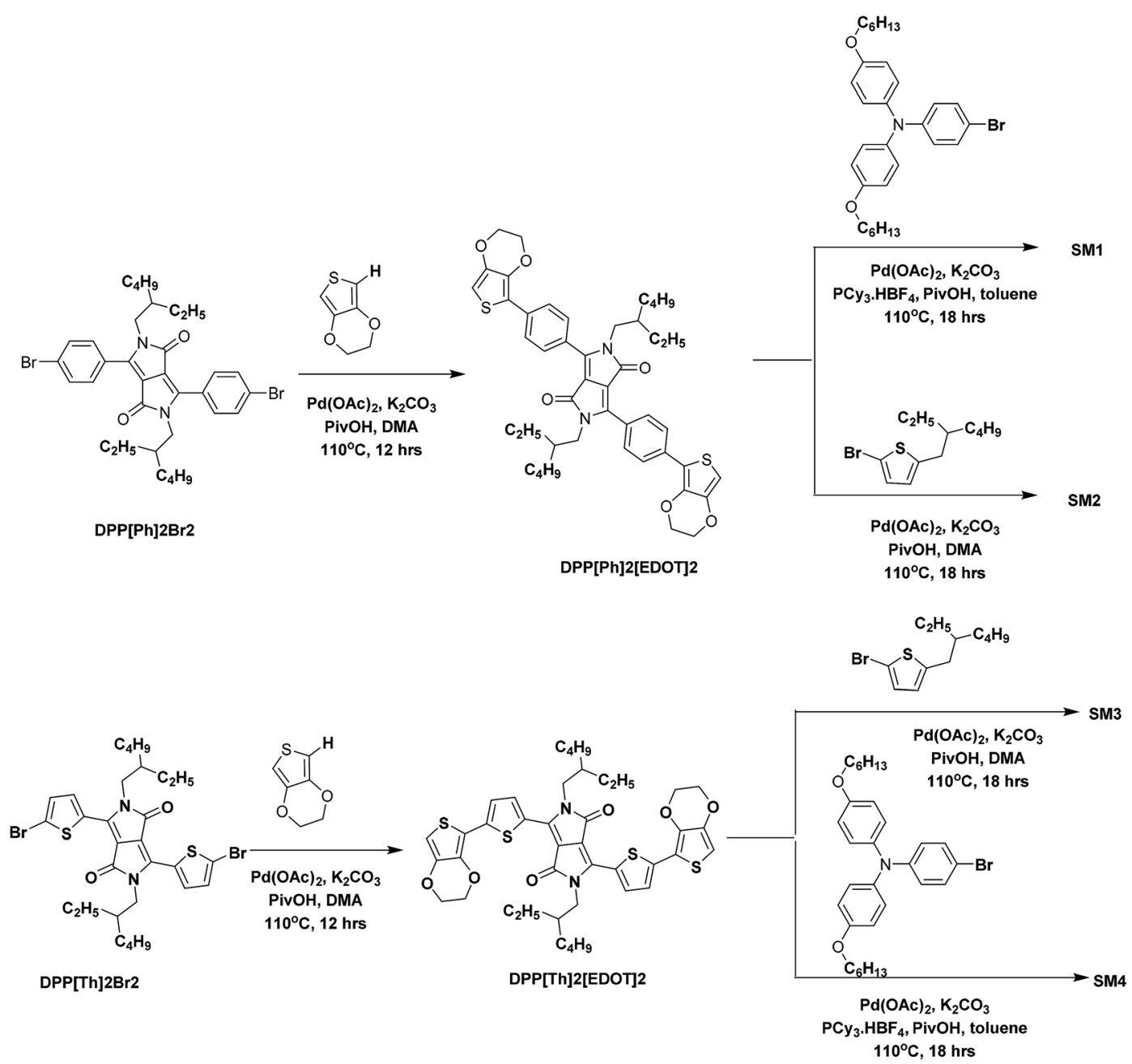

Scheme 1 Synthesis of SM1-SM4 via the direct $\mathrm{C}-\mathrm{H}$ arylation reaction. 

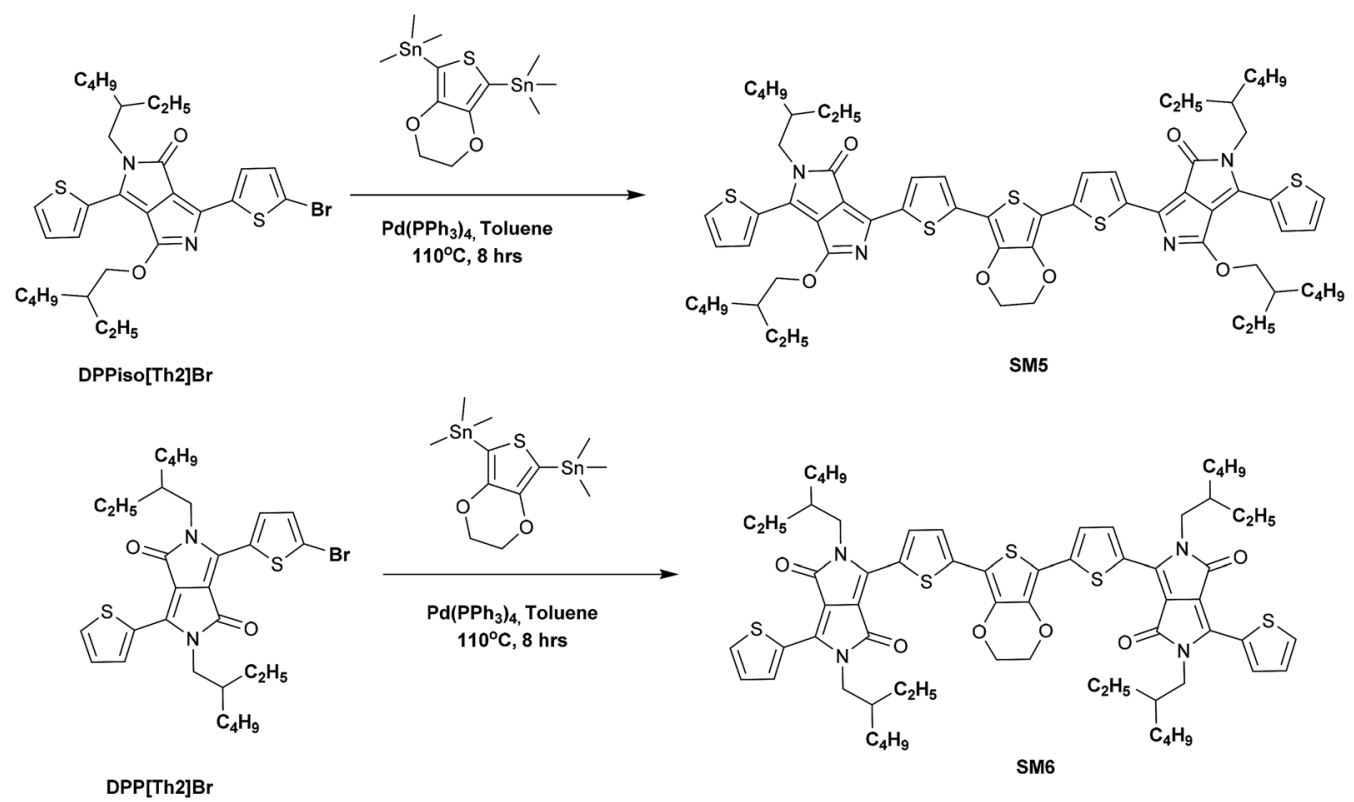

Scheme 2 Synthesis of SM5 and SM6 via the Stille coupling reaction.

solvents but the other three molecules only have fair solubility, including chloroform, toluene, tetrahydrofuran, $o$-dichlorobenzene and dichloromethane, which is attributed to the long branched alkyl chains on the DPP unit.

\subsection{Optical properties}

The UV-Vis absorption spectra of SM1-6 in dichloromethane and as a film state are displayed in Fig. 2. The optical band gaps calculated from the onset wavelength of the absorption spectra (in $\mathrm{CH}_{2} \mathrm{Cl}_{2}$ ) are listed in Table 1. The absorption peak at 350 to $500 \mathrm{~nm}$ could be attributed to the $\pi-\pi^{*}$ electronic transitions of the conjugated backbone and the broad distinct peak in the wavelength range of 500 to $800 \mathrm{~nm}$ arose from the intramolecular charge transfer transitions (ICT) between the donor and acceptor moieties in the molecules. DPP flanked by benzene units shows a high molar absorption coefficient with absorption maxima at $541 \mathrm{~nm}$ and $529 \mathrm{~nm}$ for SM1 and SM2, respectively. TPA end capped SM1 shows a broader absorption than alkyl thiophene end capped SM2, which is because the former contains two bulk triphenyl amine units. SM3 and SM4 exhibit maximum absorptions at longer wavelengths $(600-750 \mathrm{~nm})$ compared to SM1 and SM2, due to the fact that in general ${ }^{11-19}$ diketopyrrolopyrrole (DPP) flanked with a thiophene unit has better conjugation (it forms a more planar conformation) than that flanked with benzene. A red shifted absorption was observed for triphenylamine end capped SM4 $\left(\lambda_{\max }=692 \mathrm{~nm}\right)$ compared to alkyl thiophene end capped SM3 $\left(\lambda_{\max }=676 \mathrm{~nm}\right)$, due to triphenylamine being a stronger donor than alkyl thiophene.

SM5 and SM6 (with an A-D-A architecture) are isomers with the alkyl chains connected to different atoms $(\mathrm{O}$ or $\mathrm{N})$ in the DPP core. SM5 with one alkyl chain connected to O of the DPP core shows an absorption maximum at $685 \mathrm{~nm}$, which is red shifted compared to that $(644 \mathrm{~nm})$ of the other isomer, SM6, which has both alkyl chains connected to two $\mathrm{N}$ in DPP. The results indicate that the substituents on the diketopyrrolopyrrole backbone also affect the optical properties of the DPP containing molecules. Surprisingly, when one of the alkyl chains is attached to $\mathrm{O}$ of the ketone in DPP, the conjugation length of the whole molecule increases. It seems that the ketone group on DPP will disrupt the conjugation of the backbone.

The SM1-SM6 films on quartz substrates were prepared by the drop casting method and their normalized absorption spectra are also displayed in Fig. 2. A strong red shift is observed in the absorption of the film samples compared to the corresponding solution spectra for all molecules. In addition, the absorption peaks of the films are also broader than those of the solutions, providing evidence that the DPP containing molecules have strong $\pi-\pi$ stacking in the solid state. Moreover, the absorption profiles of the SM5 and SM6 films extend to close to $1000 \mathrm{~nm}$, therefore they can be regarded as low band-gap small molecules. As expected, phenyl flanked DPP (SM1 and SM2) shows larger $E_{\mathrm{g}}$ values (1.82 $\mathrm{eV}$ and $1.93 \mathrm{eV}$, respectively) than those of thienyl flanked DPP SM3 and SM4 $(1.63 \mathrm{eV}$ and $1.57 \mathrm{eV}$, respectively) ${ }^{56} \mathrm{SM} 5$ and SM6 have smaller $E_{\mathrm{g}}$ values ( $1.57 \mathrm{eV}$ and $1.55 \mathrm{eV}$, respectively, close to other A-D-A type DPP containing molecules reported before ${ }^{56}$ ) than SM1-4, due to these molecules containing two DPP units.

\subsection{Electrochemical properties}

The square-wave voltammograms of SM $x$ molecules measured in $\mathrm{TBAPF}_{6} / \mathrm{CH}_{2} \mathrm{Cl}_{2}$ electrolyte solution are displayed in Fig. 3. SM4 containing the strongly electron donating triphenylamine (TPA) and easily oxidized thiophene conjugated connector has the lowest first oxidation potential of $+0.39 \mathrm{~V}$. The first oxidation peaks for SM1 (containing electron donating triphenylamine) and SM3 (thiophene connector) are $+0.59 \mathrm{~V}$ and $+0.51 \mathrm{~V}$, 

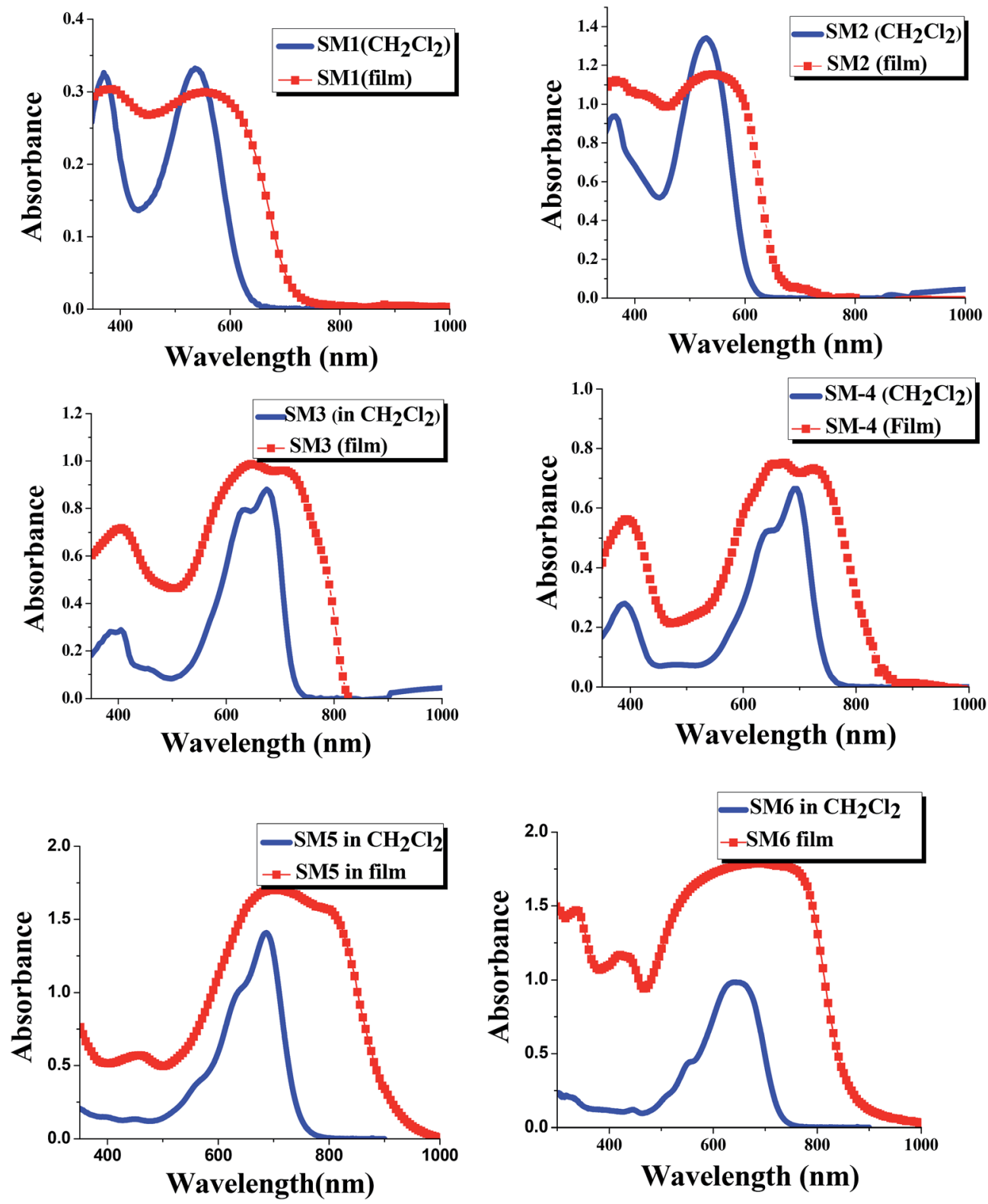

Fig. 2 UV-Vis absorption spectra of SM1-6 in dichloromethane and in the film state (the concentration of all molecules is $6 \times 10^{-5} \mathrm{M}$ ).

Table 1 Optical and electrochemical properties of SM1-SM6 molecules

\begin{tabular}{|c|c|c|c|c|c|c|c|}
\hline \multirow[b]{2}{*}{ Small molecules } & \multicolumn{2}{|l|}{ UV-vis absorption } & \multirow[b]{2}{*}{$1^{\mathrm{st}} E_{1 / 2}^{a}(\mathrm{~V} v s . \mathrm{Ag} / \mathrm{AgCl})$} & \multirow[b]{2}{*}{$\operatorname{HOMO}^{b}(\mathrm{eV})$} & \multirow[b]{2}{*}{$\begin{array}{l}\lambda_{\text {onset }} \\
(\mathrm{nm})\end{array}$} & \multirow[b]{2}{*}{$E_{0-0}^{c}(\mathrm{eV})$} & \multirow[b]{2}{*}{$\operatorname{LUMO}^{d}(\mathrm{eV})$} \\
\hline & $\begin{array}{l}\lambda_{\max } \\
\text { in } \mathrm{CH}_{2} \mathrm{Cl}_{2}(\mathrm{~nm})\end{array}$ & $\begin{array}{l}\lambda_{\max } \\
\text { in film }(\mathrm{nm})\end{array}$ & & & & & \\
\hline SM1 & 369,541 & 377,559 & 0.59 & -5.29 & 681 & 1.82 & -3.47 \\
\hline SM2 & 361,529 & 362,554 & 0.86 & -5.56 & 641 & 1.93 & -3.63 \\
\hline SM3 & 403,676 & 405,651 & 0.51 & -5.21 & 757 & 1.63 & -3.58 \\
\hline SM4 & 406,692 & 392,667 & 0.37 & -5.07 & 771 & 1.57 & -3.5 \\
\hline SM5 & 685 & 709 & 0.64 & -5.32 & 795 & 1.55 & -3.77 \\
\hline SM6 & 644 & 689 & 0.80 & -5.49 & 785 & 1.60 & -3.89 \\
\hline
\end{tabular}

${ }^{a} \mathrm{FeCp}_{2}{ }^{+/ 0}=+0.50 \mathrm{~V}(v s . \mathrm{Ag} / \mathrm{AgCl})$ in $\mathrm{TBAPF}_{6} / \mathrm{CH}_{2} \mathrm{Cl}_{2} \cdot{ }^{b}$ The HOMO energy level was calculated from the half wave potential of oxidation according to the empirical equation $E_{\mathrm{HOMO}}=-\left(E_{1 / 2}+4.5\right) \mathrm{V}$ by assuming the energy level of ferrocene to be $-4.5 \mathrm{eV}$ below the vacuum level $\left(E_{1 / 2}(\mathrm{~V}) v s\right.$. NHE). ${ }^{c}$ The energy gap $\left(E_{0-0}\right)$ was calculated from the onset wavelength of the UV-Vis spectrum according to the equation $E_{\text {gap }}=1240 / \lambda_{\text {onset }}{ }^{d}$ LUMO $=$ $\mathrm{HOMO}+E_{0-0}$. 


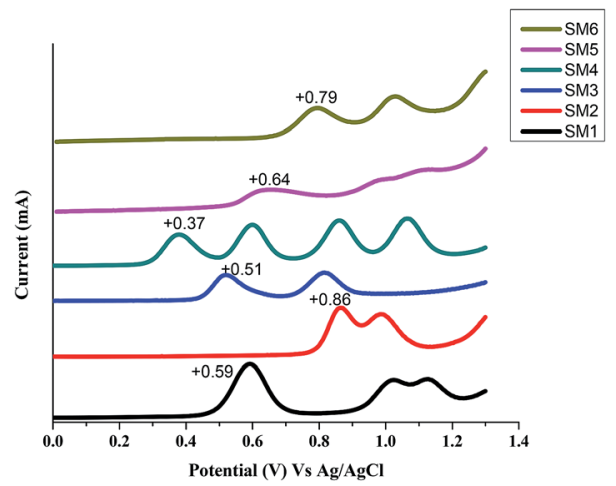

Fig. 3 Square wave voltammograms of $\mathrm{SM} 1-\mathrm{SM} 6$ in $\mathrm{CH}_{2} \mathrm{Cl}_{2}$ (electrolyte: $0.1 \mathrm{M} \mathrm{TBAPF}_{6}$ in $\mathrm{CH}_{2} \mathrm{Cl}_{2}$; working electrode: platinum. Scan rate: $0.1 \mathrm{~V} \mathrm{~s}^{-1}$ ).

respectively, which are lower than those of the other 3 molecules. Interestingly, all SM molecules have more than 1 oxidation peak at a potential between $+0.37-1.2 \mathrm{~V}$ ( $v s$. $\mathrm{Ag} / \mathrm{AgCl})$ : SM4 even has four oxidation peaks at this potential range. Therefore besides the oxidation of the $\pi$ electron on the molecular backbone, oxidation also occurs on the DPP and triphenylamine units. SM5 and SM6 are isomers, SM5 has three oxidation peaks but SM6 has only two peaks. The results suggest that on the DPP unit, when the alkyl chains connect to the $\mathrm{O}$ atoms of the ketone groups, the non-bonded electrons on the $\mathrm{N}$ of the pyrrole ring will also be oxidized.

The energies of the highest-occupied molecular orbital (HOMO), calculated from the first oxidation potential of the molecules, are illustrated in Fig. 4. The LUMO (lowestunoccupied molecular orbital) levels were calculated from the $\mathrm{HOMO}+E_{\mathrm{g}}\left(E_{\mathrm{g}}\right.$ is the on-set energy of the UV/Vis absorption spectrum (in $\left.\mathrm{CH}_{2} \mathrm{Cl}_{2}\right)$ ) and both the HOMO and LUMO are also summarized in Fig. 4 and Table 1. The benzene flanked DPP molecules (SM1 and SM2) have HOMO levels at $-5.29 \mathrm{eV}$ and $-5.56 \mathrm{eV}$, respectively, whereas the HOMO energy levels of thiophene flanked DPP (SM3 and SM4) are $-5.21 \mathrm{eV}$ and $5.07 \mathrm{eV}$, respectively. Comparing the HOMO levels of the SM1/ SM2 and SM4/SM3 pairs, it exhibits obviously that the molecules containing TPA as an ending group have higher HOMO levels, consistent with TPA being a stronger donor (than alkyl

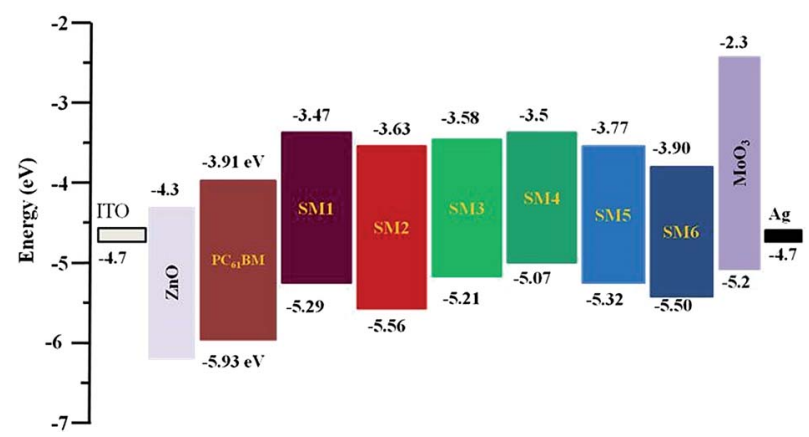

Fig. 4 Frontier orbital energy levels of SM1-6, PC ${ }_{61} B M$ as well as the electron and hole transporting materials used in this study. thiophene) in leveling the HOMO energy of the molecule. The HOMO energy levels for A-D-A type molecules (SM5 and SM6) are $-5.32 \mathrm{eV}$ and $-5.49 \mathrm{eV}$, respectively, due to both compounds containing two acceptors. Furthermore, the alkyl chain substituted on the ketone group of DPP will reduce the band gap energy as revealed by the absorption spectra (see Fig. 2) but it also raises both the HOMO and LUMO energy levels, which may not be a good property since the value of $V_{\mathrm{oc}}$ of the resulting OPV cell will decrease. Overall the LUMO energy levels of all molecules (SM1-6) are higher than the LUMO energy levels of $\mathrm{PC}_{61} \mathrm{BM}$, which was used generally as an acceptor in organic photovoltaics, indicating that the photogenerated excitons can efficiently dissociate at the p-type small molecules/PCBM acceptor interface and then transport the electron to the cathode. ${ }^{57,58}$ For applications in organic photovoltaics (OPVs), the HOMO level of p-type molecules is also critical, the molecule with lower HOMO may result in lowering the value of $J_{\mathrm{sc}}$ but increasing the value of $V_{\mathrm{oc}}$ of the corresponding cell. It is a dilemma for designing p-type molecules for OPV applications. However, if the HOMO level is lower than that of the hole transporting material, (such as $\mathrm{MoO}_{3}$ in this study), the hole cannot move to the anode through the hole transporting layer. The data illustrated in Fig. 4 reveal that only SM4 has the HOMO level higher than the HOMO of the hole transporting materials. In other words, the dissociated hole cannot transport to the anode efficiently for the cell based on SM4.

\subsection{Density functional theory (DFT) calculations}

To assess the optimized molecular geometry and frontier orbital (HOMO and LUMO) distribution of these SMx molecules, density functional theory (DFT) calculations were carried out using Gaussian09 at the B3LYP/6-31G* basic set, and the results are displayed in Fig. 5. The electron density of the HOMO distributes all over the backbone of the molecule (which includes triphenylamine, EDOT and thiophene), whereas the LUMO is contributed to mainly from the electron withdrawing DPP units. A DPP moiety with strong $\pi-\pi$ stacking and planar structure would synergistically reinforce the intermolecular interaction to enhance the transport properties. The HOMO and LUMO distributions also conclude that an effective intermolecular charge transfer occurs in the SMx films, which is consistent with the results observed in the absorption spectra in $\mathrm{CH}_{2} \mathrm{Cl}_{2}$ solution and film state (Fig. 2). A similar frontier orbital distribution was observed in other DPP containing molecules that were reported in the literature. ${ }^{12,59-62}$ The frontier orbital distributions for these six molecules are very similar. Therefore, the photovoltaic performance of these small molecules will not be attributed to the distribution of their frontier orbitals even SM1-4 have D1-D2-A-D2-D1 structures but the structures of SM5 and SM6 are A-D-A type.

\subsection{Photovoltaic performance}

The inverted solar cells based on these SM $x$ small molecule donors (as well as the P3HT reference) were fabricated with a device architecture of ITO/ZnO/SMx: $\mathrm{PC}_{61} \mathrm{BM} / \mathrm{MoO}_{3} / \mathrm{Al}$, and 


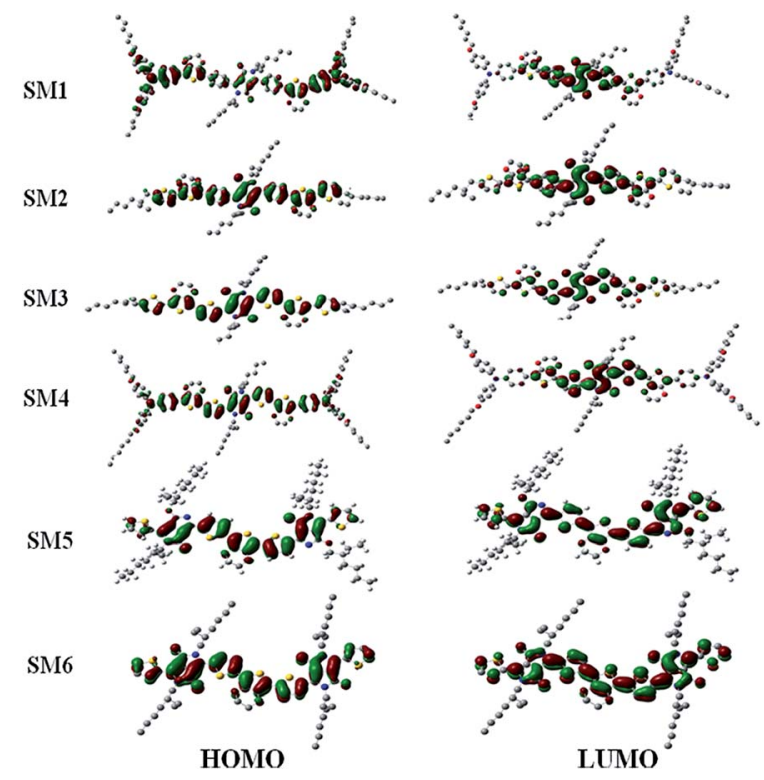

Fig. 5 Frontier orbital distribution of the SM1-6 molecules.

the current density-voltage $(J-V)$ curves of the best performance devices for each molecule are displayed in Fig. S1, (ESI $\dagger$ ). The corresponding photovoltaic data of the optimized cells are summarized in Table 2. All cells show rather poor power conversion efficiency (PCE) even after optimizing the compositions (the donor/acceptor ratios, solvents and concentrations) and processes (such as spin coating rate, adding additive, solvent and thermal annealing). SM1 and SM4, having the triphenyl amine group on the edge, exhibit extremely low values of $J_{\mathrm{sc}}$ of $0.2-0.3 \mathrm{~mA} \mathrm{~cm}{ }^{-2}$. That is why the high efficiency small molecules recently reviewed by Nguyen ${ }^{6}$ et al. contain no triphenyl amine groups. This is probably due to their molecule planarity, therefore a serious aggregation occurs at the active layer as reported in other TPA-DPP containing molecules..$^{20,59,63}$ We found that the SM1 (or SM4)/PCBM active film is rather rough as observed by the naked eye. The poor film morphology as well as high HOMO could be the reasons for the low $J_{\mathrm{sc}}$. As expected, SM2 and SM6 with low HOMO levels (compatible to $\mathrm{MoO}_{3}$, see Fig. 4) have better photovoltaic performances and SM2 having the lowest HOMO resulted in the highest value of $V_{\text {oc }}$ of the cell. Nevertheless, the values of $J_{\text {sc }}$ and FF of SM2 and SM6 based cells are much lower than those based on P3HT, probably due to the LUMO of these two molecules not being high enough for efficient exciton dissociation..$^{12,61,64}$ The inverted cell based on SM3 achieves the highest value of $J_{\mathrm{sc}}$ but the value of $V_{\mathrm{oc}}$ is lower than that for those based on SM2 and SM6, due to SM3 having broad absorption (see Fig. 2) and the highest LUMO, but the HOMO is also very high. SM6 although has very broad absorption but its LUMO level is not higher enough (only $0.02 \mathrm{eV}$ higher than the n-type PCBM), therefore the $J_{\mathrm{sc}}$ of the corresponding cell is not as high as that for the cell based on SM3. SM6 and SM5 are isomers however the cell based on SM6 has much higher PCE than that based on SM5. SM5 although has proper frontier orbitals energy level (compatible with the electron and hole transporting layers) and broad absorption profile but exhibits very poor photovoltaic performance. It is because of its low solubility (in chlorobenzene or dichlorobenzene), therefore the SM5/PCBM active film is very rough, resulting in low PCE. Overall the highest PCE of the inverted cells based on these SMx molecules is only about $1 \%$.

\section{Conclusion}

In conclusion, we have synthesized four D1-D2-A-D2-D1 type DPP containing small molecules, SM1-4, using an effective direct $\mathrm{C}-\mathrm{H}$ activation reaction, which has the advantage of easy purification and few synthetic steps. DPP-containing SM5 and SM6, which have an A-D-A structure, were synthesized by the Stille coupling reaction. All molecules were designed for application in bulk heterojunction small molecule solar cells (SMSCs). The physicochemical properties of these small molecule donors revealed that a change of the terminal group or DPP core impacts their solubility, and their optical and electrochemical properties. All molecules showed broad absorption

Table 2 Device characteristics of the solar cells based on SMx molecules ${ }^{a}$

\begin{tabular}{|c|c|c|c|c|c|c|}
\hline $\begin{array}{l}\text { Donor } \\
\text { (D) }\end{array}$ & $\begin{array}{l}\mathrm{SM} x / \mathrm{PC}_{61} \mathrm{BM} \\
\text { ratio }(\mathrm{w} / \mathrm{w})\end{array}$ & $\begin{array}{l}\text { Annealing temperature } \\
\left({ }^{\circ} \mathrm{C}\right)\end{array}$ & $J_{\mathrm{sc}}\left(\mathrm{mA} \mathrm{cm}^{-2}\right)$ & $V_{\mathrm{oc}}(\mathrm{V})$ & FF (\%) & PCE (\%) \\
\hline SM1 & $1: 1$ & As-spun & 0.21 & 0.73 & 29.24 & 0.04 \\
\hline \multirow[t]{4}{*}{ SM2 } & $1: 3$ & As-spun & 2.83 & 0.78 & 29.68 & 0.65 \\
\hline & & 80 & 3.13 & 0.73 & 33.28 & 0.76 \\
\hline & & 100 & 2.88 & 0.82 & 29.72 & 0.70 \\
\hline & & 120 & 3.02 & 0.81 & 29.97 & 0.73 \\
\hline \multirow[t]{4}{*}{ SM3 } & $3: 1$ & As-spun & 2.3 & 0.49 & 37.46 & 0.42 \\
\hline & & 80 & 2.57 & 0.54 & 38.28 & 0.53 \\
\hline & & 100 & 2.87 & 0.53 & 35.64 & 0.54 \\
\hline & & 120 & 5.56 & 0.53 & 34.35 & 1.01 \\
\hline SM4 & $1: 1$ & As-spun & 0.32 & 0.44 & 27.81 & 0.04 \\
\hline SM5 & $1: 1$ & 140 & 1.04 & 0.66 & 26.27 & 0.18 \\
\hline \multirow[t]{2}{*}{ SM6 } & $1: 1$ & As-spun & 2.72 & 0.54 & 43.5 & 0.67 \\
\hline & & 140 & 3.78 & 0.63 & 43.75 & 1.04 \\
\hline P3HT & $1: 1$ & 140 & 7.83 & 0.62 & 69.92 & 3.39 \\
\hline
\end{tabular}

${ }^{a}$ Solvent: chlorobenzene; concentration of SMx: $2 \mathrm{wt} \%$; spin rate: $500-1000 \mathrm{rpm}$, 60 s; additive (DIO) is not good for this donor system. 
and (besides SM4) the HOMO and LUMO energy levels were suitable to be used as p-type molecules for PCBM based organic photovoltaic devices. However, due to the relatively low lying LUMO and serious self-aggregation, the highest PCE of the best performance molecules was only ca. 1\%. Nevertheless, the results clearly demonstrate that the DPP unit represents an interesting building block for the design of push-pull molecules with various optical and electronic properties.

\section{References}

1 L. Dou, J. You, Z. Hong, Z. Xu, G. Li, R. A. Street and Y. Yang, Adv. Mater., 2013, 25, 6642-6671.

2 R. F. Service, Science, 2011, 332, 293.

3 J. Roncali, Acc. Chem. Res., 2009, 42, 1719-1730.

4 Y. Lin, Y. Li and X. Zhan, Chem. Soc. Rev., 2012, 41, 42454272.

5 Y. Chen, X. Wan and G. Long, Acc. Chem. Res., 2013, 46, 26452655.

6 S. D. Collins, N. A. Ran, M. C. Heiber and T.-Q. Nguyen, Adv. Energy Mater., 2017, 7, 1602242-1602287.

7 Y. Qiao, Y. Guo, C. Yu, F. Zhang, W. Xu, Y. Liu and D. Zhu, J. Am. Chem. Soc., 2012, 134, 4084-4087.

8 H. Zhong, J. Smith, S. Rossbauer, A. J. P. White, T. D. Anthopoulos and M. Heeney, Adv. Mater., 2012, 24, 3205-3211.

9 A. K. Palai, J. Lee, S. Das, J. Lee, H. Cho, S. U. Park and S. A. Pyo, Org. Electron., 2012, 13, 2553-2560.

10 S. L. Suraru, U. Zschieschang, H. Klauk and F. Wurthner, Chem. Commun., 2011, 47, 1767-1769.

11 B. Walker, A. B. Tamayo, X. D. Dang, P. Zalar, J. H. Seo, A. Garcia, M. Tantiwiwat and T. Q. Nguyen, Adv. Funct. Mater., 2009, 19, 3063-3069.

12 A. B. Tamayo, B. Walker and T. Q. Nguyen, J. Phys. Chem. C, 2008, 112, 11545-11551.

13 S. Loser, C. J. Bruns, H. Miyauchi, R. P. Ortiz, A. Facchetti, S. I. Stupp and T. J. Marks, J. Am. Chem. Soc., 2011, 133, 8142-8145.

14 J. Huang, C. Zhan, X. Zhang, Y. Zhao, Z. Lu, H. Jia, B. Jiang, J. Ye, S. Zhang, A. Tang, Y. Liu, Q. Pei and J. Yao, ACS Appl. Mater. Interfaces, 2013, 5, 2033-2039.

15 M. Chen, W. Fu, M. Shi, X. Hu, J. Pan, J. Ling, H. Li and H. Z. Chen, J. Mater. Chem. A, 2013, 1, 105-111.

16 J. Liu, B. Walker, A. Tamayo, Y. Zhang and T. Q. Nguyen, Adv. Funct. Mater., 2013, 23, 47-56.

17 B. Walker, J. Liu, C. Kim, G. C. Welch, J. K. Park, J. Lin, P. Zalar, C. M. Proctor, J. H. Seo, G. C. Bazan and T. Q. Nguyen, Energy Environ. Sci., 2013, 6, 952-962.

18 Y. Lin, P. Cheng, Y. Li and X. A. Zhan, Chem. Commun., 2012, 48, 4773-4775.

19 J. Liu, Y. Sun, P. Moonsin, M. Kuik, C. M. Proctor, J. Lin, B. B. Hsu, V. Promarak, A. J. Heeger and T. Q. Nguyen, Adv. Mater., 2013, 25, 5898-5903.

20 O. P. Lee, A. T. Yiu, P. M. Beaujuge, C. H. Woo, T. W. Holcombe, J. E. Millstone, J. D. Douglas, M. S. Chen and J. M. Frechet, Adv. Mater., 2011, 23, 5359-5363.
21 J. Huang, H. Jia, L. Li, Z. Lu, W. Zhang, W. He, B. Jiang, A. Tang, Z. Tan, C. Zhan, Y. Li and J. Yao, Phys. Chem. Chem. Phys., 2012, 14, 14238-14242.

22 E. Ripaud, D. Demeter, T. Rousseau, E. Boucard-Cétol, M. Allain, R. Po, P. Leriche and J. Roncali, Dyes Pigm., 2012, 95, 126-133.

23 L. Biniek, B. C. Schroeder, C. B. Nielsen and I. J. McCulloch, Mater. Chem., 2012, 22, 14803-14813.

24 S. Y. Liu, M. Shi, J. Huang, Z. Jin, X. Hu, J. Pan, H. Li, A. K. Y. Jen and H. Z. Chen, J. Mater. Chem. A, 2013, 1, 2795-2805.

25 J. Zhang, D. Y. Kang, S. Barlow and S. R. Marder, J. Mater. Chem., 2012, 22, 21392.

26 Q. Guo, J. Dong, D. Wan, D. Wu and J. You, Macromol. Rapid Commun., 2013, 34, 522-527.

27 S.-Y. Liu, W.-Q. Liu, J.-Q. Xu, C.-C. Fan, W.-F. Fu, J. Ling, J.-Y. Wu, M.-M. Shi, A. K. Y. Jen and H.-Z. Chen, ACS Appl. Mater. Interfaces, 2014, 6, 6765-6775.

28 S. Y. Liu, W. F. Fu, J. Q. Xu, C. C. Fan, H. Jiang, M. Shi, H. Y. Li, J. W. Chen, Y. Cao and H. Z. Chen, Nanotechnology, 2014, 25, 014006.

29 A. Facchetti, L. Vaccaro and A. Marrocchi, Angew. Chem., Int. Ed., 2012, 51, 3520-3523.

30 L. G. Mercier and M. Leclerc, Acc. Chem. Res., 2013, 46, 15971605.

31 Y. Tan and J. F. Hartwig, J. Am. Chem. Soc., 2011, 133, 33083311.

32 M. Wakioka, Y. Nakamura, Y. Hihara, F. Ozawa and S. Sakaki, Organometallics, 2013, 32, 4423-4430.

33 D. J. Schipper and K. Fagnou, Chem. Mater., 2011, 23, 15941600.

34 D. J. Burke and D. J. Lipomi, Energy Environ. Sci., 2013, 6, 2053-2066.

35 S. Y. Liu, H. Y. Li, M. M. Shi, H. Jiang, X. L. Hu, W. Q. Li, L. Fu and H. Z. Chen, Macromolecules, 2012, 45, 9004-9009.

36 S. M. Tuladhar, M. Azzouzi, F. Delval, J. Yao, A. A. Y. Guilbert, T. Kirchartz, N. F. Montcada, R. Dominguez, F. Langa, E. Palomares and J. Nelson, ACS Energy Lett., 2016, 1, 302308.

37 J. Roncali, P. Blanchard and P. Frère, J.Mater. Chem., 2005, 15, 1589-1610.

38 D. Demeter, T. Rousseau and J. Roncali, RSC Adv., 2013, 3, 704-707.

39 N. F. Montcada, R. Domínguez, B. Pelado, P. de la Cruz, E. Palomares and F. Lang, J. Mater. Chem. A, 2015, 3, 11340-11348.

40 C. Wang, C. J. Mueller, E. Gann, A. C. Y. Liu, M. Thelakkat and C. R. McNeill, J. Mater. Chem. A, 2016, 4, 3477-3486.

41 K. Zhang, B. Tieke, J. C. Forgie and P. J. Skabara, Macromol. Rapid Commun., 2009, 30, 1834-1840.

42 Y. Zhu, I. Heim and B. Tieke, Macromol. Chem. Phys., 2006, 207, 2206-2214.

43 I. Perepichka, E. Levillain and J. Roncali, J. Mater. Chem., 2004, 14, 1679-1681.

44 M. Turbiez, P. Frure, M. Allain, C. Videlot, J. Ackermann and J. Roncali, Chem.-Eur. J., 2005, 11, 3742-3752. 
45 C. J. Mueller, C. R. Singh and M. Thelakkat, J. Polym. Sci., Part B: Polym. Phys., 2016, 54, 639-648.

46 F. Grenier, B. Réda Aïch, Y.-Y. Lai, M. Guérette, A. B. Holmes, Y. Tao, W. W. H. Wong and M. Leclerc, Chem. Mater., 2015, 27, 2137-2143.

47 M. Shaker, J.-H. Lee, C. K. Trinh, W. Kim, K. Lee and J.-S. Lee, RSC Adv., 2015, 5, 66005-66012.

48 M. Shaker, C. K. Trinh, W. Kim, H. Kim, K. Lee and J.-S. Lee, New J. Chem., 2015, 39, 4957-4964.

49 C. Y. Liu, H. Zhao and H. Yu, Org. Lett., 2011, 13, 4068-4071.

50 C.-Y. Chen, S.-J. Wu, J.-Y. Li, C.-G. Wu, J.-G. Chen and K.-C. Ho, Adv. Mater., 2007, 19, 3888-3891.

51 Y.-Q. Wu, H.-C. Chen, Y.-S. Yang, S. H. Chang and C.-G. Wu, J. Polym. Sci., Part A: Polym. Chem., 2016, 54, 1822-1833.

52 W. Zeng, Y. Cao, Y. Bai, Y. Wang, Y. Shi and M. Zhang, Chem. Mater., 2010, 22, 1915-1925.

53 F. Zhang, K. Jiang, J. Huang, C. Yu, S. Li and S. M. Chen, J. Mater. Chem. A, 2013, 1, 4858-4863.

54 G. L. Zhang, H. Bala, Y. M. Cheng, D. Shi, X. J. Lv and Q. J. Yu, Chem. Commun., 2009, 45, 2198-2200.
55 B. Zhao, K. Sun, F. Xue and J. Ouyang, Org. Electron., 2012, 13, 2516-2524.

56 J. W. Lee, Y. S. Choi and W. H. Jo, Org. Electron., 2012, 13, 3060-3066.

57 Y. He and Y. F. Li, Phys. Chem. Chem. Phys., 2011, 13, 19701983.

58 C. J. Brabec, C. Winder, N. S. Sariciftic, J. C. Hummelen, A. Dhanabalan, P. A. van $\mathrm{Hal}$ and R. A. J. Janssen, $A d v$. Funct. Mater., 2002, 12, 709-712.

59 C. Ji, L. Yin, L. Wang, T. Jia, S. Meng, Y. Sun and Y. Li, J. Mater. Chem. C, 2014, 2, 4019-4026.

60 B. Walker, X. Han, C. Kim, A. Sellinger and T.-Q. Nguyen, ACS Appl. Mater. Interfaces, 2012, 4, 244-250.

61 B. Sun, W. Hong, Z. Yan, H. Aziz and Y. Li, Adv. Mater., 2014, 26, 2636-2642.

62 C. Li, Y. Chen, Y. Zhao, H. Wang, W. Zhang, Y. Li, X. Yang, C. Ma, L. Chen, X. Zhua and Y. Tu, Nanoscale, 2013, 5, 9536-9540.

63 J. Chen, M. Xiao, F. Meng, L. Duan, H. Tan, Y. Wang, Y. Liu, R. Yang and W. Zhu, Synth. Met., 2015, 199, 400-407.

64 J. H. Seo, Synth. Met., 2012, 162, 748-752. 